Ebisu Ebisu

Études japonaises Études japonaises

$58 \mid 2021$

2011-2021 : crises, ruptures et nouvelles dynamiques.

Dix ans après la triple catastrophe du 11 mars

\title{
Iwai-shima, île antinucléaire
}

祝島、反核の島

Iwai-shima, No-Nuke Island

Philippe Pelletier

\section{OpenEdition \\ Journals}

Édition électronique

URL : https://journals.openedition.org/ebisu/6174

DOI : 10.4000/ebisu.6174

ISSN : 2189-1893

Éditeur

Institut français de recherche sur le Japon à la Maison franco-japonaise (UMIFRE 19 MEAE-CNRS)

Édition imprimée

Date de publication : 1 novembre 2021

Pagination : 325-357

ISSN : 1340-3656

Référence électronique

Philippe Pelletier, « Iwai-shima, île antinucléaire », Ebisu [En ligne], 58 | 2021, mis en ligne le 01 novembre 2021, consulté le 14 avril 2022. URL : http://journals.openedition.org/ebisu/6174 ; DOI :

https://doi.org/10.4000/ebisu.6174 


\section{Iwai-shima, île antinucléaire}

\section{Philippe Pelletier}

祝島、反核の島

フィリップ・ペルティエ

Iwai-shima, No-Nuke Island

Philippe Pelletier

\ Mots-clés : insularité, nucléaire, exode rural, géographie politique, matsuri

L'auteur : Philippe Pelletier est docteur en géographie, diplômé en langue et civilisation japonaises, professeur émérite de l'univ. Lumière Lyon 2 et membre de l'UMR 5600. Il a notamment publié $L a$ Japonésie (1997, Prix Shibusawa-Claudel et Grand prix de l'Académie de Marine), Extrême-Orient, invention d'une histoire et d'une géographie (2011) et L'Invention du Japon (2020).

Résumé : Depuis 1982, les habitants d'Iwai-shima, petite île située dans la partie occidentale de la mer intérieure de
Seto, s'opposent au projet de construction d'une centrale nucléaire prévue en face, de l'autre côté d'une passe. Leurs motifs : perte d'une zone de pêche, enlaidissement du paysage, endommagement du milieu, modification du mode de vie, décision venue d'en haut sans réelle concertation. Mais, démographiquement minoritaires au sein de la commune de Kaminoseki-chō (département de Yamaguchi), ils n'arrivent pas à obtenir une majorité en leur faveur au sein du conseil municipal. Leur forte tradition communautaire (fête de Kanmai, système kabuuchi de travail collectif...), malgré l'exode rural, et la ténacité des pêcheurs forts de leurs droits sur l'espace maritime a favorisé leur union. 
】キーワード

島国性、原子力、農村移住、地政学、祭り

著者

フィリップ・ペルティエ：地理学博士。日本 語・日本文明の学位を持つ。リヨン第 2 大 学名誉教授、共同研究ユニット5600 のメ ンバー。主な著書に、La Japonésie（1997 年、渋沢・クローデル賞、海洋アカデミー 賞グランプリ)、Extrême-Orient, invention d'une histoire et d'une géographie（2011 年）、 L'Invention du Japon（2020 年）などがある。
要旨

瀬戸内海の西側にある祝島の島民は、1982 年から、対岸に計画されている原子力発電所 の建設に反対してきた。その理由は、漁場の 喪失、景観の損失、環境破壊、生活様式の変 化、実質的協議もないままの高圧的決定であ る。しかし、彼らは上関町 (山口県) では少 数であったため、市議会において過半数を得 ることができなかった。農村への移住にもか かわらず、彼らのコミュニティにおける堅い 伝統（神舞祭り、「株内」という集団労働の システムなど）や、海洋空間においてその権 利が守られている漁師たちの粘り強さは、彼 らの結束を断固たるものにした。 \eywords: Insularity, Nuclear, Rural Exodus, Political Geography, Matsuri

The Author: Philippe Pelletier is a Doctor in Geography, has a degree in Japanese language and civilisation, is professor emeritus at Université Lumière Lyon 2, and a UMR 5600 Member. His works include La Japonésie (1997, Shibusawa-Claudel Prize and Grand Prix de l'Académie de Marine), Extrême-Orient, invention d'une histoire et d'une géographie (2011) and L'Invention du Japon (2020).

Abstract: Since 1982, the residents of Iwaishima, tiny island in the west of the Seto Inland Sea, have opposed plans to build a nuclear power plant opposite them across the channel. Their motives: loss of fishing grounds, disfigurement of the landscape, environmental damage, changes to their way of life, and a highlevel decision that was taken without any real concertation. But as a demographic minority in Kaminoseki (Yamaguchi Prefecture), they are unable to obtain a majority in the municipal council. Their strong community traditions (Kanmai festival, the kabu-uchi system of communal work, etc.), despite rural exodus, and their fishermen's tenacious defence of their rights over the marine area, have unified them. 


\title{
Iwai-shima, île antinucléaire
}

\author{
Philippe Pelletier*
}

Jusqu'à l'accident de Fukushima en 2011, rares étaient les travaux en langue non-japonaise qui abordaient la question électronucléaire au Japon. Moimême, à part quelques cartes de localisation ou allusions, je ne l'avais pas développée ${ }^{1}$. En mettant de côté mes propres convictions, j'avais été bercé et berné comme d'autres par le discours dominant sur un Japon hypertechnologique, efficace et discipliné où un accident du type de Tchernobyl en 1986 n'était tout simplement pas envisageable. Étant au Japon à cette époque-là, c'est d'ailleurs ce que j'avais largement entendu.

Avec l'accident de Fukushima, il fallait reconsidérer la question. Il existe par exemple plusieurs cas où la population locale a refusé l'installation d'une centrale nucléaire. Leur analyse, qui relève de la sociologie ou de la politologie, relève également de la géographie, ma discipline, puisque la mise en situation territoriale révèle d'autres aspects comme le rapport au milieu, à la nature, à la communauté locale. Un lieu peut cristalliser un mouvement - qu'il soit de refus ou d'acceptation.

1. Par exemple, la carte "Localisation des sources d'énergie ", dans Pelletier Philippe, "Le Japon ", in Roger Brunet (dir.), Géographie Universelle, Chine, Japon, Corée, 1994, p. 344 .

* Professeur à l’université Lumière Lyon 2. 
Lors de ma thèse sur la mer Intérieure de 1984 à 1986, j'avais entendu parler de la lutte qui venait de s'engager contre un projet de centrale nucléaire sur l'île d'Iwai-shima 祝島 dans la commune de Kaminoseki-chō 上関町, département de Yamaguchi. Je ne l'avais toutefois exposée qu'en une page, sans développer, puisque ma problématique générale portait sur les questions d'accessibilité, d'éloignement insulaire et de construction de ponts (Pelletier 1992 : 182).

En mars 2012, Sugita Kurumi, une collègue sociologue japonaise travaillant à Lyon organise, avec ses amis japonais et français regroupés dans une association, la projection inédite en France d'un film réalisé par Kamanaka Hitomi 鎌中ひとみ. Intitulé Comme l'abeille qui fait tourner la terre (Mitsubachi no haoto to chikyū no tenkai ミツバチの羽音と地球の転回), il s'agit d'un long métrage documentaire. Sorti au Japon en 2010, donc avant Fukushima, il s'est retrouvé sous les feux de l'actualité car il est centré sur les questions de l'énergie et sur la lutte antinucléaire des habitants d'Iwai-shima.

J'ai voulu en savoir davantage et me suis donc rendu à deux reprises sur cette petite île, en juin 2012 puis en août 2016. La seconde fois, j'étais accompagné par une équipe de tournage - la réalisatrice Christine Bouteiller et le caméraman Swann Dubus - afin de réaliser un film documentaire ${ }^{2}$. Cette seconde configuration de recherche sur le terrain soulève bien entendu des questions. Principalement : est-ce que la présence de la caméra et l'orientation filmique du séjour allaient entraver une démarche scientifique?

La réponse est non, car cela m'a aussi permis d'ouvrir des portes, de récolter des voix et de voir les choses sous un autre angle. Les habitants ne rechignaient ni à parler ni à témoigner. Loin d'être un frein, mon statut d'étranger m'a également favorisé car les interlocuteurs sortaient de l'entre soi insulaire. Dix ans après la catastrophe de Fukushima, mon enquête de terrain dont la brièveté a été compensée par une documentation importante donne maintenant l'occasion de montrer les différents aspects d'une lutte antinucléaire au Japon.

2. Bouteiller Christine, Le Géographe et l'île, film documentaire, Scotto Productions, 70 min, 2018. 


\section{Chūden se tourne vers Kaminoseki}

Il faut remonter à l'après-guerre. L'État, les grandes entreprises et les principaux partis de droite comme de gauche s'engagent très tôt dans l'électronucléaire au Japon. Appuyés par la politique américaine, symbolisée par le discours Atoms for Peace du président Eisenhower aux Nations unies le 8 décembre 1953, ils entendent substituer au nucléaire militaire, considéré comme nuisible depuis les bombardements atomiques de Hiroshima et de Nagasaki les 6 et 9 août 1945, un nucléaire civil vu comme une source d'énergie remarquable (Pelletier 2013).

Outre les mastodontes de Tepco (Tokyo Electric Company) à Tokyo et de Kepco (Kansai Electric Company) à Osaka, la compagnie régionale privée Chūden 中電 (abréviation de Chūgoku denryoku kabushiki gaisha 中国電力株式会社, Société anonyme d'électricité du Chūgoku), est l'une des premières à se lancer au Japon dans ce domaine. Son périmètre comprend les départements de Hiroshima, d'Okayama, de Tottori, de Shimane et de Yamaguchi. Dès 1961, soit six ans après la loi de programmation de 1955, Chūden ouvre un département de recherches nucléaires ${ }^{3}$. En 1974, elle construit à Kajima, un lieu très reculé de la péninsule de Shimane du côté de la mer du Japon, un premier réacteur de type BWR couplé d'un deuxième en 1989 (Arima 2012).

L'État japonais saisit l'occasion du choc pétrolier de 1973 pour dépasser les nombreuses résistances des habitants et relancer le programme nucléaire. Les lois dites dengen sanpo $\overline{0}$ 電源三法 instaurent en 1974 une politique d'aides visant à séduire les collectivités locales. L'avis de la municipalité concernée par un projet d'installation de centrale nucléaire constitue désormais le préalable incontournable d'une pyramide de décisions. Mais les nouveaux projets d'installation nucléaire de Chūden capotent. Et pour cause... L'« allergie au nucléaire » (genpatsu arerugī 原発アレルギー) est puissante dans la région et la ville où l'entreprise a son siège social : Hiroshima. Un membre du gouvernement japonais déclare d'ailleurs en 1985 qu'une tentative d'implantation nucléaire à proximité serait « un suicide pour la compagnie » (Lesbirel $1998: 23$ ).

3. Chūgoku denryoku 50 nenshi 中国電力50年史, Hiroshima, Chūgoku denryoku KK, 2011, 298 p. 
Un projet de centrale nucléaire dans la région, à Hōkoku-chō 豊北町 (département de Yamaguchi) sur le San.in-dō 山陰道, échoue au cours des années 1970. Les dirigeants politiques et économiques en concluent que les pressions venant du haut (gouverneur, Chūden et MITI) ont été trop insistantes. Il convient désormais d'agir en douceur et de passer par «le bas » (Dusinberre 2012 : 154-155). C'est-à-dire d'abord convaincre les élus locaux et sensibiliser la population. Les accidents nucléaires qui se multiplient au cours des années 1980 dans le monde ou au Japon ne font pas vraiment basculer l'opinion publique japonaise, mais la préoccupent.

Kaminoseki-chō offre au moins trois avantages. La commune est située en bordure de mer, ce qui permet d'acheminer le combustible importé ou les équipements lourds, et de disposer d'une grande quantité de liquide de refroidissement. Elle est proche de la mégalopole du San.yōdō 山陽道 et de son marché de consommateurs en électricité (usines, villes). Elle est dominée, au niveau local et départemental, par une élite politique et économique conservatrice située dans le cœur dirigeant du Parti libéral-démocrate (Jimintō 自民党, le clan Kishi-Satō-Fujimoto-Abe).

Kaminoseki-chō hérite aussi d'une histoire et d'une géographie dont les traits permettent de comprendre l'émergence d'un mouvement antinucléaire.

\section{Une île de mi-agriculteurs mi-pêcheurs}

Iwai-shima $\left(7,56 \mathrm{~km}^{2}\right)$ est l'une des 436 îles habitées du Japon. Située à soixante-dix kilomètres à vol d'oiseau de Hiroshima, elle semble isolée en plein milieu de la mer intérieure de Seto. Elle se trouve en effet au large occidental de l'île de Naga-shima 長島 (axe ouest-est), elle-même située à la pointe de la péninsule de Murotsu (axe sud-nord). Il s'agit en quelque sorte d'une "sur-sur-île » (autrement dit : l'île de l'île, l'île au carré, voire au cube). 


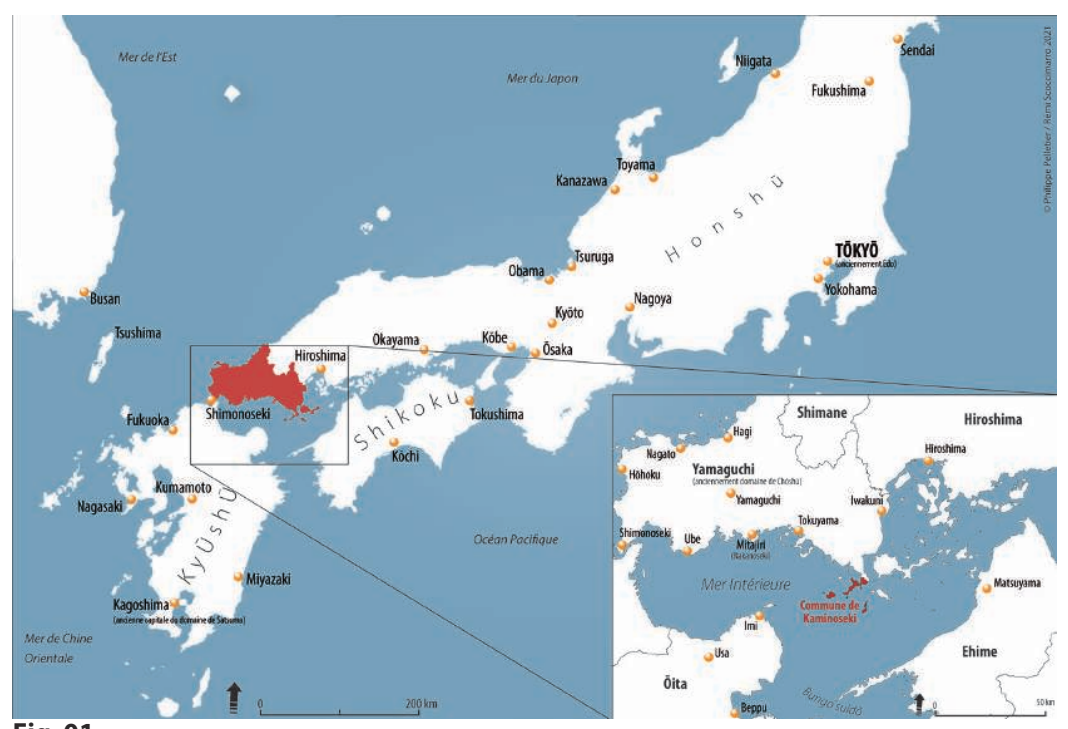

\section{Fig. 01}

Carte de Kaminoseki.

Il ne faut toutefois pas en rester à cette apparence topographique, car l'île est historiquement placée sur l'axe de civilisation qui relie le Nord de Kyūshū, avec le continent eurasiatique plus loin, aux anciennes cités ou capitales japonaises du Kinai 機内 (Kaminoseki-chō shihensan iinkai 1985). Les trois routes maritimes qui passaient plus ou moins à distance du littoral de la mer Intérieure se confondaient ici en un passage obligé : le détroit de Kaminoseki avec son port éponyme, à la pointe orientale de Naga-shima, du côté de Honshū. Iwai-shima reste ainsi au contact de nombreux flux économiques, culturels et humains au cours des siècles (Fukushima 1989). 


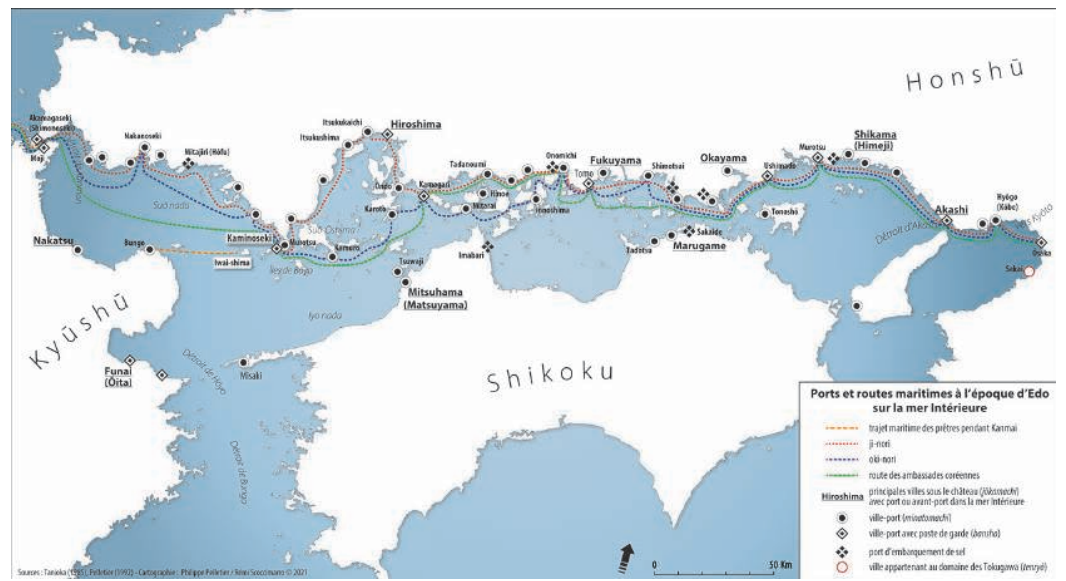

\section{Fig. 02}

Carte de la mer Intérieure.

L'essor de la navigation à vapeur au XIx ${ }^{\mathrm{e}}$ siècle puis l'ouverture des lignes de chemin de fer qui arrivent à Shimonoseki 下関 en 1901 transforment le mini-centre de Kaminoseki en périphérie. La marginalisation d'Iwai-shima s'accélère à partir de la période dite de Haute croissance ( $k o ̄$ do seichō 高度成長, 1955-1973) : exode rural massif en direction des industries et des villes de la mégalopole sur le Hondo 本土 (le Mainland), vieillissement démographique, déclin de l'agriculture et de la pêche, déréliction (fermeture de l'école, départ du médecin...). La population d'Iwai-shima qui compte 3342 habitants en 1947, son summum, ne représente plus qu'un millier de personnes en 1985, quarante ans plus tard. Et moins de quatre-cents personnes de nos jours.

Cette évolution remet paradoxalement Kaminoseki au centre du jeu économique et politique à la fin du $\mathrm{Xx}^{\mathrm{e}}$ siècle en vertu de sa localisation maritime. Car, au début des années 1980, Chūden recherche justement pour son projet de centrale nucléaire un endroit situé au bord de la mer qui ne soit ni trop près, ni trop loin de la mégalopole. Elle repère la baie de Ta-noura 田ノ浦 à l'extrémité occidentale de Naga-shima, invisible des populations qui habitent de l'autre côté de l'île dans le bourg de Kaminoseki. Mais en face se trouve Iwai-shima, séparée de trois kilomètres par un bras de mer. 


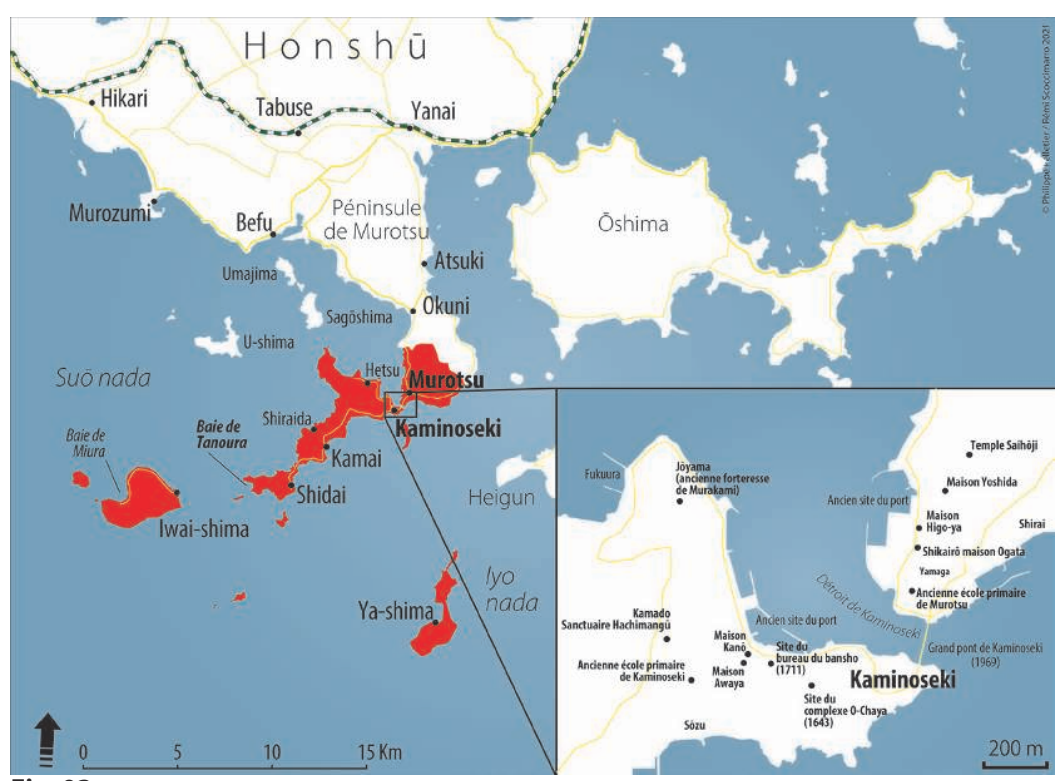

\section{Fig. 03}

Carte de Naga-shima.

C'est le début d'un long et vaste mouvement d'opposition porté par les habitants de l'île ${ }^{4}$. Au-delà des traits communs à une petite île (étroitesse, enclosure, dynamique entre terre et mer, entre fermeture et ouverture), Iwai-shima possède en effet des caractéristiques propres qui expliquent la réaction de ses habitants et qui font la différence par rapport à tant de bourgades japonaises ayant accepté le nucléaire.

4. Yamato Sadao prés., Iwaishima nisshi, genpatsu yoteichi o mokuzen ni miru shima ni ikite 祝島日誌原発予定地を目前にみる島に生きて (Notes d'Iwai-shima, vivre sur l'île d'où l'on voit le projet de centrale nucléaire), Shimonoseki, Genpatsu iran! Shimonoseki no kai 下関原発いらん! 下関の会, 2013, 452 p. Nasu Keiko 那須佳子, Chüden-san, sayōnara, Yamaguchi-ken Iwaishima genpatsu to tatakau shimabito no kiroku 中電さん、さようならー 山口県祝島原発とたたかう島人の記録 (Au revoir, Messieurs de Chūden, mémoires sur les insulaires qui combattent le nucléaire à Iwaishima dans le département de Yamaguchi), Tokyo, Sōshi-sha 創史社, 2007, 210 p. 
Contrairement aux îles voisines comme Ya-shima 八島 ou U-shima 牛島, sa composition socioéconomique est variée, son identité culturelle est forte. Hormis un hameau de trois maisons, il s'agit d'un «village de mi-agriculteurs mi-pêcheurs" (hannō-hangyo-son 半農半漁村). S'y ajoutent quelques activités tertiaires (commerce, administration, tourisme...). Les insulaires y ont maintenu un système original de partage des terres dit kabu-uchi 株内 ( "entre parts »). Reposant sur un usage collectif de la force de travail, il n'a pas été touché par la réforme agraire de 1947. Bien qu'il soit moins actif de nos jours, il assure une cohésion sociale ancestrale en combinant liens de voisinage et rapports familiaux qui outrepassent le seul cadre des relations fondées sur la propriété foncière.

Le taux d'endogamie est historiquement très élevé à Iwai-shima, mais les familles ont organisé un subtil réseau local et cantonal de matrimonialité qui a évité la consanguinité débilitante, même si un dicton affirme qu'on produit sur l'île des génies ou des idiots. Dans le bourg où les maisons basses entourées de hauts murs faits de galets dits nerihei 練り塀 s'accolent les unes aux autres, tout le monde est peu ou prou cousin de quelqu'un.

Sur un terroir aux pentes raides et couronné par un plateau montueux qui culmine à $357 \mathrm{~m}$, l'agriculture s'effectue sur champ, à part quelques rizières dans le secteur de Miura 三浦. La fruiticulture y domine avec les agrumes et surtout les nèfles biwa 枇杷 très réputées, et de bon rapport. Elle bénéficie d'un climat idéal (chaleur plus moindre humidité) et d'une pédologie appropriée 5 . La récolte, le séchage et la vente à la fin de la saison hivernale des algues hijikiひじき (sargassum fusiformis) donnent un produit très apprécié des consommateurs urbains. Il semble rapporter davantage que la pêche proprement dite, dont les techniques traditionnelles à la ligne (ippon-tsuri - 本釣り) ou à la palangre (haenawa 延縄) subissent la concurrence des grandes pêcheries. Les poissons sont destinés au marché régional

5. Les sols sont granitiques (andésite) ou gneissiques. Les précipitations annuelles sont inférieures à $1500 \mathrm{~mm}$. La moyenne du mois le plus froid (janvier) est de $7^{\circ}$, celle du mois le plus chaud (juillet) de $24,9^{\circ}$. La neige tombe parfois en janvier ou en février, une à deux fois selon les années, mais sans tenir. Le mois le plus arrosé est juin qui correspond à la saison des pluies baiu 梅雨, parfois renforcée par les "pluies diluviennes " (shūchū gōu 集中豪雨). Chiffres de la station météorologique voisine de Ya-shima sur une période de quatre ans (1953-1957) (Matsubara et al. 1971 : 71). 
jusqu’à Hiroshima (trichiure tachiuo 太刀魚, bar suzuki 鱸, sébaste mebaru 鮴 et hareng sayori 細魚).

L'économie est touchée par l'exode rural, mais, à l'instar d'autres îles de la mer Intérieure, la pêche décline proportionnellement moins que l'agriculture en nombre d'actifs. Iwai-shima compte environ un millier de paysans en 1965, moins d'une centaine en 1995, soit dix fois moins en une trentaine d'années, contre trois centaines de pêcheurs en 1965 et une centaine en 1995, soit trois fois moins. Malgré la disparition de la pêche à la sardine, la structure du monde halieutique reste grosso modo en place. Elle s'articule autour de sept familles propriétaires de filets, ou amimoto 網元, qui engagent chacune jusqu'à une vingtaine de personnes (les Kanata, Yoshida, Sakai, Amakusa, Nakamura, Okada...).

La double ou triple activité (pêche, agriculture, services) introduit une horizontalité dans un système par ailleurs vertical puisqu'il existe une poignée plus riche de familles traditionnellement liées à la terre et à l'agriculture.

\section{Tradition de mobilité et ancrage de Kanmai, la « danse des dieux»}

Le travail saisonnier à l'extérieur (dekasegi 出稼ぎ) remonte à la féodalité. Il concernait autrefois les brasseries de saké dans la région d'Osaka ou encore l'embarcation sur les baleiniers, puis, pendant la Haute croissance, l'embauche dans les usines de la mégalopole.

L'émigration outre-mer qui s'enclenche à partir de 1890 et se poursuit pendant la première moitié $\mathrm{du} \mathrm{xx}^{\mathrm{e}}$ siècle repose en partie sur cette tradition de mobilité. Elle s'explique aussi par la pression démographique, quoique celle-ci soit moins élevée sur Iwai-shima que dans certaines autres îles comme la proche Suō-Ōshima 周防大島, mais surtout par l'insertion dans un système politico-économique lié à la colonisation japonaise et pensé à trois échelles : régionale, nationale et internationale (Ichioka 1988; Stanlaw 2006 : 34-45; Ishikawa 1997).

En 1881, David Kalakaua (1836-1891), roi de Hawaï, entreprend une tournée mondiale pour faire venir de la main-d'œuvre. Son pays s'est en effet lancé dans l'agriculture de plantation (canne à sucre, ananas...), mais sa population s'est brutalement réduite à cause du choc épidémiologique provoqué par la venue des Américains et des Européens (O 2010; Nordyke 
\& Matsumoto 1977 : 163). Hawaï manque de bras. Après la Californie, le Japon est le deuxième pays que Kalakaua visite. Il y reste une quinzaine de jours, du 4 au 18 mars 1881, rencontrant l'empereur Meiji à deux reprises. Son idée d'une "Union et fédération des nations et des souverains asiatiques » est rejetée par le gouvernement japonais, mais celle d'un déplacement de main-d'œuvre est retenue. Hawaï n'étant pas encore fédéré aux États-Unis (ce qu'il deviendra en 1900), la délivrance de visas pour les travailleurs étrangers y est très souple.

Intervient alors Inoue Kaoru 井上馨 (1836-1915). Natif d'un village de la région de Suō 周防, ce ministre des Affaires étrangères est issu du clan de Chōshū 長州, pilier du nouveau régime de Meiji. C'est également un ami d'enfance d'un autre homme fort originaire de la même région, Itō Hirobumi 伊藤博文 (1841-1909). En 1847, Inoue encouragea Masuda Takashi 益田孝 (1848-1938) à fonder une compagnie de commerce axée sur le transport maritime qui, par fusions successives (banque, Bussan, Minière et Sucrière), aboutit à la création du zaibatsu 財閥 Mitsui 三井 en 1900.

Sur le conseil d'Inoue, Masuda enrôle Robert Walker Irwin (18441925). Cet Américain possède une compagnie maritime qui établit la première liaison transpacifique régulière. Appointé ministre représentant Hawaï au Japon lors de la venue du roi Kalakaua, il est également chargé du bureau hawaïen d'immigration. Masuda lui souffle l'idée de puiser sa main-d'œuvre auprès des paysans pauvres et non qualifiés de Suō-Ōshima. La politique de déflation lancée au début des années 1880 par le gouvernement japonais de Matsukata malmène en outre l'agriculture et favorise la mobilité rurale.

Iwai-shima fournit quelques émigrés, mais proportionnellement en moins grand nombre que les îles voisines. Ses exilés partent par ordre décroissant d'importance vers Hawaï, la Californie, Karafuto 樺太 (Sakhaline), la Corée et la Mandchourie. À la fin du XIx ${ }^{e}$ siècle, une quarantaine d'entre eux relèvent de la « migration contractuelle » dite kan.yaku imin 官約移民 (1889-1891) et sept de l'émigration privée (1895-1896). D'autres partent au cours des années 1920. Leur succès se traduit soit par un retour au pays natal une fois fortune acquise, soit par des donations au village (pour un temple, la fête de l'île, une école, une statue...) (Dusinberre 2012, op. cit.).

Cette émigration, largement coloniale et liée au réseau politico-économique de l'ex-Chōshū devenu Yamaguchi, donne une touche conservatrice, 
nationaliste et impériale à l'élite d'Iwai-shima, voire à certains de ses habitants. On la retrouve dans leurs rapports particuliers avec le clan KishiAbe originaire de cette partie de Yamaguchi située entre Shimonoseki et Kaminoseki. Kishi Nobusuke 岸信介 (1896-1987), grand-père de l'ex-Premier ministre Abe Shinzō 安倍晋三, par exemple, s’est réfugié pendant plusieurs mois sur Iwai-shima après avoir été arrêté comme criminel de guerre de rang A et relâché sans procès le 24 décembre 1945.

Il a bénéficié de l'aide de Fujimoto Manjirō 藤本万次郎 (1898-1984), un ami d'enfance natif de l'île. Ce Fujimoto occupe tout au long de sa vie un grand nombre de fonctions au sein des pêcheries japonaises, à Shimonoseki notamment, où il est conseiller municipal pendant la guerre et l'aprèsguerre. C'est un acteur politique de l'ombre très efficace puisqu'il préside après 1945 les associations de soutien de plusieurs hommes forts du Japon, dont Abe Shintarō 安倍晋太郎 (1924-1991), le père d'Abe Shinzō. Quant à Abe Akie 安倍昭恵, l'épouse de Shinzō, elle s'est récemment rendue à plusieurs reprises sur Iwai-shima.

Les insulaires d'Iwai-shima sont particulièrement fiers de leur fête : Kanmai 神舞. Alias la "danse des dieux ", elle a lieu à peu près tous les quatre ans depuis plusieurs siècles. Elle célèbre l'histoire de moines naufragés revenus d'un pèlerinage à Kyoto au cours du Moyen-Âge, et qui auraient, en remerciement de leur sauvetage, offert de précieuses plantes aux habitants de "L'Île de la prière » (= Iwai-shima) $)^{6}$. Cette matsuri (sai) 祭り qui relève autant d'un festival populaire que d'un rite religieux combine plusieurs événements, dont les deux principaux sont la parade nautique kaidenma 權伝馬 et la tenue d'une kagura 神楽, une mascarade shintō dont le personnage central est Kōjin 荒神, le « dieu rude » ou le « dieu sauvage » (Irie 1975; Martzel 1982; Berthier 1981).

Selon tous les témoignages, Kanmai est le ciment culturel, social et identitaire d'Iwai-shima (Kunihiro \& Kunihiro 2016). Elle reflète un attachement essentiel qui aurait freiné l'exode rural comparativement aux îles voisines, disent plusieurs interlocuteurs. On le constate lors de son déroulement : ceux qui sont partis vers la mégalopole reviennent pour y participer,

6. Cette signification correspond à l'écriture idéographique. Mais il existe d'autres hypothèses, notamment celle qui renvoie à iwa 岩, la pierre, car l'île est rocheuse. 
et la population de l'île double voire triple à ce moment-là. C'est sans surprise que Kanmai devient un enjeu au cours de la lutte contre la centrale.

\section{La décision municipale de 1983}

La question nucléaire vient bousculer le traditionnel ordonnancement sociologique de la "communauté » insulaire. La petite partie de l'élite terrienne qui soutient le projet de Chūden est délégitimée. Inversement, les pêcheurs qui veulent d'abord sauver leur espace d'activité sont revalorisés en tant que fer de lance de la lutte. Le retour sur l'île d'anciens habitants ou de leurs descendants, auxquels s'ajoutent quelques néo-ruraux ijūsha 移住者 (les « immigrés »), pèse également dans la dynamique.

Selon la législation japonaise, c'est le conseil municipal qui doit donner en amont l'autorisation de construire une centrale nucléaire sur son territoire avec une majorité des deux tiers. Sa composition sociologique et spatiale issue des élections démocratiques est déterminée par le périmètre géographique de la commune. Or, le bourg ( $c h o ̄$ 町) de Kaminoseki résulte d'une fusion en 1958 de quatre anciennes communes : Kaminoseki, Murotsu, Ya-shima et Iwai-shima. Son regroupement a été imposé par l'État conformément à la politique nationale.

Les quatre anciennes communes sont désormais considérées comme de simples districts ou chiku 地区 sur le plan administratif et statistique. Malgré la fusion subsistent des identités et des rivalités. Le pont attendu par les élus locaux passe depuis 1969 au-dessus du détroit de Kaminoseki, mais il n'a en rien freiné le recul démographique et économique de la commune, contrairement à ce que ses prescripteurs annonçaient. Il relie les deux bourgades portuaires situées de part et d'autre du détroit, Murotsu et Kaminoseki, de façon physique mais pas forcément socioculturelle.

À Murotsu, le Parti communiste japonais (Nihon kyōsantō 日本共産党) est historiquement bien implanté grâce à la présence d'ouvriers sur le port, de parias burakumin et d'un courant anti-belliciste. Celui-ci n'oublie pas le rôle de l'armée japonaise dont les bases locales ont attiré les bombardements 
pendant la guerre ${ }^{7}$. Après la guerre, le nouveau maire de Murotsu est même un communiste de l'ancienne génération. La fusion communale affaiblit bien évidemment le poids et les possibilités de ce parti. Mais il se maintient. Jusqu'au renouvellement municipal de février 1986, le seul conseiller de Kaminoseki-chō qui s'oppose aux seize autres conseillers partisans du nucléaire est un communiste, Koyanagi Akira 小柳あきら

Le rapport de force démographique et donc politique change de façon radicale. Alors que la part de la population d'Iwai-shima représente près d'un quart (23,9 \%) de Kaminoseki-chō au moment de la fusion en 1958, elle tombe à 17,6\% en 1985 au début de la lutte antinucléaire, puis à $15 \%$ en 2010. Sur un plan strictement comptable, les îliens d'Iwai-shima se retrouvent donc de plus en plus minoritaires au sein de la commune, ce qui se répercute mécaniquement sur leur représentation et leur poids politiques.

Or le système démocratique japonais fonctionne encore largement sur une base socio-spatiale. Les clans ancrés territorialement donnent le ton audelà de toute considération doctrinale. Les populations de chaque ancienne commune de Kaminoseki-chō qui veulent être représentées votent en fonction de leurs intérêts. Les listes de conseillers municipaux sont donc soigneusement dosées. Cette géographie politique pèse dans l'approbation initiale du projet nucléaire, puis dans l'opposition qui se cristallise sur Iwai-shima.

Le sort se joue une première fois au cours de l'été 1981. Une poignée d'hommes politiques régionaux bien reliés au pouvoir central échangent alors avec Yoshinaga Shigeru 吉永茂, ancien maire de Hirao 平生町 (19551962), une ville proche de Kaminoseki. Ce Yoshinaga était le secrétaire de Satō Eisaku 佐藤栄作 (1901-1975), ancien Premier ministre (1964-1972), également originaire du département de Yamaguchi et membre du clan

7. «Kaminoseki-chō hatten no genshiryoku wa nani ka, sono rekishi o furikaeru " 上関町発展の原子力発電所は何か その歴史を振り返る (Le nucléaire et son développement à Kaminoseki-chō, c'est quoi? Retour sur son histoire), Chōshu shinbun 長州新聞, 29 mars 2003.

8. Donc avant que le Parti communiste japonais ne change peu à peu son soutien au nucléaire civil, révision entamée en janvier 1986, accélérée lors de son $23^{\text {e }}$ congrès de 2004 puis conclue par le "retrait du nucléaire " (genpatsu no tettei 原発の徹底) décidé par le comité central du 3 juillet 2011. 
Kishi-Abe. Yoshinaga contacte ensuite Kanō Arata 加納新, un ancien collègue de classe qui est devenu maire de Kaminoseki ${ }^{9}$.

Kanō Arata descend de l'une des grandes familles de commerçants de sa commune, la ton.ya 問屋 de Kaga-ya 加賀屋 qui dirige la municipalité de pères en fils. À son retour de Sibérie après la guerre, il devient membre de la coopérative de pêche de Kaminoseki, puis son président. En 1959, un an après la fusion communale, il est élu maire avec le soutien du Parti libéral-démocrate. Il bat alors Moritomo Hiromitsu 守友博光, prêtre du Hachimangū 八幡宮 et ancien responsable de la coopérative de pêche d'Iwai-shima. Cette victoire traduit le déplacement du balancier géopolitique local de l'île vers le petit centre urbain de Kaminoseki-Murotsu. Kanō Arata effectue un premier mandat, cède sa place à un homme de Murotsu, puis revient au premier rang de 1971 à 1983 . Utilisant ses connexions politiques, il fait construire le fameux pont sur le détroit de Kaminoseki grâce à une aide directement demandée auprès du Premier ministre Satō Eisaku.

Élu en février 1982, le nouveau conseil municipal de Kaminoseki dégage une majorité a priori favorable au nucléaire. Selon le maire Kanō, "si les citoyens approuvent, on demande la centrale». Pour les dirigeants régionaux et nationaux, il faut transformer l'essai, tout en ne parlant pas trop de la question, afin d'éviter une opposition intempestive. Des rumeurs circulent en effet au sein de la commune et du département, mais il n'y a encore rien d'officiel. Le 17 novembre, une association d'opposants locaux au nucléaire civil se constitue, l'"Association de tout cour par amour du pays " (Aikyō isshin-kai 愛郷一心会, AIK).

Les élections municipales de 1983 sont cruciales. Kanō Arata, qui a effectué quatre mandats et dont la gestion a soulevé des polémiques, est écarté. Katayama Hideyuki 片山秀行 entre en scène. Orphelin d'un père mort à la guerre, c'est le prototype de l'aventurier de l'après-guerre qui sort du rang malgré une mauvaise scolarité et l'absence d'une ascendance de notables. Conseiller municipal de Kaminoseki depuis 1978, il a été contacté par Matsunaga Tsune.ichi 松永常一 (1920-1999), alors vice-gouverneur du département de Yamaguchi, à propos du dossier nucléaire. Représentant un

9. Il s'agit bien de Kanō Arata et non, comme l'indique Martin Dusinberre, de Kanō Shin, comme on peut aussi lire cet idéophonogramme. 
nouveau souffle, c'est lui qui est choisi par le Jimintō pour mener la bataille électorale.

Le 24 avril 1983, il est élu avec 2871 voix (67,5\% des suffrages exprimés) face au candidat antinucléaire, Mukai Jōichi 向井丈一, qui recueille 2121 voix (42,5\%). Le 27 septembre 1983, dans les locaux de la mairie de Kaminoseki, et dans une atmosphère surchauffée, le conseil municipal se prononce en faveur du projet de centrale nucléaire à seize voix contre une.

\section{Iwai-shima, une minorité proche de la majorité}

Le nouveau maire Katayama confirme quelques mois plus tard la candidature (27 septembre 1985), puis la dépose auprès de Chūden (5 septembre 1988). Mais les travaux commencent officiellement bien après (13 novembre 1996). Les opposants essaient en effet de gagner du temps, de convaincre les indécis et de faire pression sur les différentes instances pour qu'elles basculent de leur côté. Les délais s'allongent entre avis officieux d'une proposition et confirmation officielle. Des sommes d'argent colossales sont en jeu. De 1984 à 2010, la commune de Kaminoseki reçoit 4,5 milliards de yens comme subventions en provenance du gouvernement, et 2,4 milliards de yens de la part de Chūden (Tabuchi 2011).

Le combat se déroule sur le plan institutionnel (élections, décisions de justice) et sur le terrain géopolitique (rapports de force, manifestations, actions), à toutes les échelles (communale, départementale, régionale, nationale, internationale). Les opposants luttent juridiquement dans plusieurs directions : la question foncière des terres et de la mer; les droits de pêche; le domaine du sanctuaire Shōhachimangū 正八幡宮 situé sur les hauteurs de Naga-shima et en partie concerné par l'expropriation; l'environnement; la légalité des travaux.

Les habitants d'Iwai-shima étant à la quasi-unanimité opposés au projet, il leur faut obtenir au sein du conseil municipal une majorité politique qu'ils n'ont pas sur le papier démographique. Ils doivent donc convaincre idéologiquement le reste de la commune. Cette stratégie est logique, puisque les taux de participation électorale restent très élevés à chaque scrutin (jusqu’à $95 \%$ des inscrits sur les listes électorales), malgré quelques variations.

Or le sentiment antinucléaire est variable dans le reste de la commune. Il est vif notamment dans les villages de pêcheurs de Naga-shima qui seraient 
proches de la centrale, moins ailleurs, surtout là où Chūden fait emménager des employés qui votent en sa faveur. S'agissant de faibles effectifs démographiques, les moindres suffrages comptent. Surtout, le système d'allégeance traditionnelle et le poids historique des notables maintiennent la logique politique sur une erre conservatrice. Le tout opère sur fond de déclin démographique qui favorise les discours promettant un avenir radieux.

Le système japonais dissocie l'élection du maire et celle des conseillers municipaux tous les quatre ans, à deux ans d'intervalle l'une de l'autre. Alors que l'élection du maire se fait à la majorité absolue, l'élection des conseillers se fait par panachage. Elle reflète davantage la variété sociale du territoire communal, ce qui permet la présence de conseillers en désaccord avec le maire.

Les opposants au nucléaire y progressent, mais ils n'arriveront pas à franchir un " plafond de verre ". Si le rapport de force ne change pas à la tête de la mairie - les élections du 26 avril 1987 reconduisent Katayama Hideyuki (avec 2835 voix, 57,2 \% des suffrages exprimés) contre Kawamoto Hiromasa 河本広正 (avec 2216 voix, 44,7 \%) - il n'en va pas de même au sein du conseil municipal. Lors de l'élection des conseillers municipaux de février 1986, les pro-nucléaires obtiennent onze sièges (ils en perdent cinq) et les antinucléaire sept (ils en gagnent six). Les opposants ratent de peu la possibilité de constituer une minorité de blocage à huit sièges. Cet épisode qui revient souvent dans leurs témoignages est d'ailleurs vécu douloureusement.

La catastrophe de Tchernobyl (26 avril 1986) ne modifie pas vraiment la donne. Il y a même une forte continuité. Certes, le corps électoral de Kaminoseki-chō, qui diminue régulièrement au fil du recul démographique, tourne autour de cinq mille votants (élections du maire en avril 1983 comme en avril 1987), puis de trois mille votants (élections du maire en septembre 2007 comme en septembre 2011). Mais le rapport numérique entre les deux camps ne change guère.

Pour les opposants à la centrale nucléaire, il oscille entre 42,5\% des suffrages (élection du maire en 1984, pratiquement le même chiffre pour l'élection de 2003 avec 42,1\%) et 46,2 \% (1991, le maximum). Même des péripéties parfois sérieuses ne changent guère la donne. Tel est le cas pour l'élection du maire le 27 avril 2003. Quelques jours plus tard, la mairesse pro-nucléaire nouvellement élue, Kanō Misuka 加納みすか, fille du clan de notables historiques Kanō, est arrêtée pour infraction au code électoral 
(manipulation suspecte d'argent). Elle démissionne. Qu'à cela ne tienne, les nouvelles élections qui s'ensuivent, le 5 mai 2003, donnent pratiquement le même nombre de voix à Kashiwabara Shigemi 柏原重海, qui la remplace dans le camp pro-nucléaire ${ }^{10}$.

Les jeux locaux semblent donc figés dès le début. Ce qui se passe en dehors de Kaminoseki paraît n'avoir qu'un faible impact. Le conservatisme clanique et traditionnel semble caractériser aussi bien les " pros " que les "antis ", même sur Iwai-shima. C'est du moins la thèse de l'historien britannique Martin Dusinberre qui ne cache pas ses sympathies pour le nucléaire dans une optique "développementaliste" (Dusinberre 2012, op. cit.). Selon lui, l'opposition radicale des habitants d'Iwai-shima s'explique largement par leur alignement auprès de leurs propres notables pour de bonnes ou de mauvaises raisons. Il met notamment en avant le rôle de Kanata Toshio 金田敏男, un descendant d'un ancien notable de l'île, un amimoto prospère, mais aussi un entrepreneur de travaux publics qui aurait basculé du côté antinucléaire parce qu'il aurait été écarté du marché de construction promis par la centrale.

Dusinberre néglige toutefois plusieurs points. Il oublie le rôle du fils Ujimoto Chōichi 氏本長一, par exemple, qui prend à contre-pied les positions pro-nucléaires de son père, Ujimoto Kuichi 氏本久一 (1922-2006), l'un des notables historiques d'Iwai-shima. Après avoir travaillé dans le Hokkaidō dans un secteur agricole intensif et chimique, Chōichi souhaite en effet promouvoir une agriculture plus biologique et "naturelle». Il la met en pratique sur l'île en créant un élevage de porcs qu'il nourrit grâce au recyclage des déchets locaux et qu'il vend à bon prix aux bouchers et restaurants de luxe de la mégalopole. Par héritage familial, il occupe en outre une place importante dans Kanmai.

Dusinberre édulcore également l'engagement important d'un personnage devenu l'une des figures du combat antinucléaire d'Iwai-shima, Yamato Sadao. Né sur Iwai-shima, fils aîné de l'une des grandes familles de l'île historiquement liée à la terre - c'est au demeurant un cousin d'Ujimoto

10. Lors des élections municipales (maire) de Kaminoseki-chō du 27 avril 2003, Kanō Sumika recueille 2001 voix $(57,8 \%)$ et Yamato Sadao 山戸貞夫 1458 voix (44,1\%). Lors des élections du 5 mai 2003, Kashiwabara Shigemi recueille 1988 voix (59\%) et Yamato Sadao 1381 voix (41\%). 
Chōichi -, il est diplômé de l'université de Shimane. D'abord employé à la mairie de Matsue, il travaille ensuite dans une entreprise de la même ville, où il monte un syndicat. En janvier 1985, lui et son épouse décident de revenir sur l'île. Il joue alors un rôle actif et important dans la lutte antinucléaire (Yamato 2013 : 32).

\section{Une nouvelle génération sur Iwai-shima}

Au-delà d'autres personnages animant la lutte, des hommes comme Shimizu Toshiyasu 清水敏保, Kimura Tsutomu 木村力 (qui vivait à Chiba, qui revient sur l'île et qui deviendra responsable de la jichikai 自治会 insulaire), Okamoto Masaaki, Abe Ichio et des femmes comme Nakamura Noriko ou Sakai Kiyoko, pour ne prendre que les figures les plus anciennes, les trajectoires d'Ujimoto Chōichi et de Yamato Sadao sont représentatives d'un double tournant : générationnel et sociologique.

Ces deux hommes-là ont en effet acquis une expérience de vie, professionnelle notamment, en dehors de l'île, dans des secteurs nouveaux de la société japonaise, tout en disposant d'une formation universitaire. Alors que leurs aînés sont empêtrés dans des valeurs traditionnelles, ils s'en affranchissent, chacun à leur manière. Ils passent d'un domaine économique à l'autre, de la fruiticulture à l'élevage chez Ujimoto, du monde paysan au monde des pêcheurs chez Yamato.

Cette translation s'effectue en vertu d'une stratégie politique. Les pêcheurs menacés de perdre un espace de travail à cause du terre-plein prévu pour accueillir la centrale nucléaire ont une importance cruciale que Yamato Sadao a bien saisie. Ils sont les premiers opposants significatifs grâce à leur " coopérative de pêcheurs" (gyokyō 漁協). En destituant Hashimoto Tadao 橋本忠夫 de sa direction (janvier 1983), pro-nucléaire et membre du conseil municipal de Kaminoseki-chō, puis en y propulsant Yamato Sadao qu'ils élisent dès son retour sur l'île en 1985 par deux tiers des 129 membres, ils bousculent les positions traditionnelles. Ils se donnent une plus grande liberté et donc une plus grande force dans leur engagement, multipliant les manifestations, les blocages, les recours...

Yamato Sadao estime que la lutte doit "s'extirper » (dakkyaku 脱却) d'une posture d' «isolement» (koritsu 孤立), où elle risque de s'enfoncer dans un « renoncement douloureux et abusif » (hibō chījō hōki 誹謗中傷放棄) 
face au rouleau compresseur des pro-nucléaires et de Chūden. Constatant l'épuisement des militants dû aux défilés à répétition dans les ruelles de l'île où personne ne vient, des manifestants devenus " des voix sans voix " (koe naki koe 声なき声), puisque cela revient à crier dans le désert, il prône une nouvelle stratégie (ibid. : 32-33). Et il est entendu.

Selon lui, il faut qu'Iwai-shima devienne " une île qui s'ouvre " (biraketa shima e 開けた島へ), qu'elle accueille des personnes, noue des contacts, bref qu'elle « apporte un grand coup d'air » (omoi küki o tsuyoku kanji-sase 重い空 気強く感じさせ). Le slogan de " ranimer la cité »(machi no shinkō 町の振興) avancé par les pro-nucléaires ayant un certain impact, il convient de se mettre sur un même plan de positivité.

En 1985, Yamato Sadao remplace Kanata Toshio à la tête de l'AIK, l'«Association de tout cœur par amour du pays », dont l'intitulé vieillot fleure un certain traditionalisme teinté de nationalisme. Il y impulse la nouvelle ligne. Kanata avait choisi une stratégie exclusiviste de défense passant par un certain repli sur l'île. Elle s'appuyait notamment sur le murahachibu 村八分 («les huit parts du village»), méthode traditionnelle d'ostracisme chez les villageois pour exclure quelqu'un de la communauté (à l'exception de deux parts - l'incendie et les funérailles - lorsque la solidarité doit être totale). Â la suite du vote du conseil municipal en faveur de la centrale le 27 septembre 1985, trois conseillers municipaux avaient ainsi été empêchés de rentrer chez eux sur l'île pendant un mois. Ils avaient trahi le mandat des insulaires (ibid. : 25). Ils sont rentrés sous escorte policière.

Selon la nouvelle stratégie, il s'agit d'être proactif au lieu d'être réactif. Le sentiment se fait jour que, même si le projet de centrale nucléaire disparaissait, cela ne résoudrait pas les problèmes de l'avenir, une thématique que mobilisent précisément les partisans du nucléaire avec leur slogan de "réactiver la cité " (machi o fukkatsu 町を復活). Avec d'autres personnes, Yamato fait entrer dans le débat, et la lutte, la thématique des alternatives économiques (énergie renouvelable, agriculture différente) et environnementales. Il encourage la diversification des actions militantes. Il sent aussi qu'il ne faut pas se couper de la partie de Kaminoseki et de Murotsu opposée au nucléaire, en particulier les pêcheurs du hameau de Shidai 四代, qui se trouvent non loin du site de la centrale.

En juin 1987, est fondée au sein de l'AIK une «Section de réveil insulaire» (Shima-okoshi bukai 島おこし部会, SOB). Cet intitulé de shima-oko$s h i$ 島おこし est dans l'air du temps. Il est véhiculé par les sociologues et les 
géographes qui observent les phénomènes de néo-ruralité au sein des petites îles éloignées du Japon. Il est également utilisé, récupéré finalement, par les instances dirigeantes comme l'a été le slogan de machizukuri 町づくり (" faire la ville », " faire la cité ») (Pelletier 2007).

Parmi l'une des premières initiatives de la SOB figure une amélioration de la commercialisation du hareng. Le poisson était pêché puis directement expédié sur Hondo. La coopérative de pêche d'Iwai-shima décide d'organiser son séchage nocturne sur l'île, ce qui apporte de la valeur ajoutée avant sa commercialisation et un gain de revenu en conséquence. La culture de biwa s'engage dans l'abandon des intrants chimiques pour jouer la carte du marché des produits biologiques. Sa vente directe est recherchée. La production d'un tōfu 豆腐 traditionnel fabriqué avec de l'eau de mer est relancée ${ }^{11}$.

Des journées d'études, des activités artistiques (concerts...) ou sportives sont organisées sur l'île en faisant venir des personnes de l'extérieur. Les écoles et les scolaires sont également impliqués. Des émissions de radio locale sont lancées ainsi qu'un journal et un blog. Le retour ou l'installation des jeunes sur l'île est encouragé, autre aspect de la dynamique générale du shima-okoshi au Japon.

On y donne davantage la parole aux vétérans qui ont une expérience d'employés dekasegi dans le secteur nucléaire et qui sont au nombre d'une vingtaine. Isobe Kazuo, l'un d'entre eux, raconte son parcours d'ouvrier sur les chantiers, qui lui a fait quitter l'île juste après la guerre puis travailler en 1975 comme nettoyeur dans le réacteur numéro deux de la centrale de Fukushima Daiichi qui venait juste d'ouvrir. Avec lui, une douzaine d'autres personnes sont venues d'Iwai-shima. Isobe a travaillé dans le secteur le plus sensible. Après trois mois, il a reçu 850 millirems de radiation, un montant équivalent à une année de travail dans une centrale, soit huit fois supérieur à la limite acceptée pour les civils (Tabuchi 2011). Il est atteint d'un cancer (Ankei 2012: 129).

D'autres hommes de l'île ont été employés comme intérimaires par Chūden dans la centrale nucléaire de Shimane et par Kepco dans celle de Suruga 駿河. Selon Paul Jobin, qui les a interrogés au printemps 2002, «ils

11. Cette recette typique de la région autrefois n'existe plus qu’à Iwai-shima. On la trouve également dans les Gotō et à Okinawa. 
furent si horrifiés par les conditions de travail qu'ils sont rapidement rentrés à Iwai-shima, où ils ont témoigné auprès de leurs congénères de la sordide réalité des centrales nucléaires, ce qui a renforcé le mouvement d'opposition " au projet de Kaminoseki (Jobin 2017) ${ }^{12}$.

La stratégie de Kanata avait entraîné le boycott de deux Kanmai, en 1984, pratiquement au début de la lutte, puis en 1988. Elle conteste notamment les prêtres pro-nucléaires du sanctuaire d'Iwai-shima, le Hachimangū. Représentant historiquement les notables de l'île qui sont les principaux financeurs de Kanmai, ces religieux incarnent la compromission. Leurs dons ne correspondent-ils pas finalement aux indemnisations promises par Chūden?

Mais l'arme du boycott est à double tranchant. Si elle constitue indiscutablement une protestation symboliquement forte, elle affaiblit à l'intérieur le sentiment communautaire et démobilise la diaspora. Vers l'extérieur, elle efface l'île par ce qui est notablement connu d'elle. Concernant le Kanmai de 1988, Yamato Sadao propose sa reprise. Puis il se conforme au vote des insulaires qui se prononcent contre, par fierté et par fatigue.

Réorientant le sentiment identitaire, il fait partie de ceux qui prônent la fin du boycott et le retour de Kanmai en 1992. L'objectif affiché est le bien des enfants, le maintien du lien entre les îliens et avec leur diaspora, rendu effectif par leur retour provisoire pendant la fête, et la volonté de se montrer à l'ensemble du Japon, y compris sous une forme touristique. Yamato Sadao mentionne explicitement que Kanmai fait partie intégrante du shima-okoshi et qu'elle constitue même une forme de shima-zukuri 島づ 〈り, de "faire l'île" comme on "fait la ville» (Yamato 2013 : 35-37). La reprise de la fête en 1992 devient un grand événement, dont beaucoup se remémorent.

12. Les photos de ces "gitans du nucléaire" d'Iwai-shima figurent dans Fukushima (1989 : 264-265). 


\section{Un nouveau fonctionnement, de nouvelles thématiques}

La nouvelle stratégie aboutit à la constitution en février 1992 d'un nouveau regroupement, l'«Association des insulaires d'Iwai-shima opposés à la construction de la centrale nucléaire de Kaminoseki " (Kaminosekigenpatsu wo tatesasenai Iwaishima-tōmin no kai 上関原発を立てさせない祝 島島民の会), abrégé en Tōmin no kai 島民の会 (TNK), qui devient l'organisation principale de la lutte sur l'île. Son fonctionnement se veut différent de "l'AIK caractérisée par le top-down " (ibid. : 39). Elle ouvre la porte aux partisans du nucléaire, elle n'est pas basée sur une représentation par foyer, ni sur la traditionnelle tripartition (en trois quartiers) au sein du bourg, mais sur l'adhésion individuelle, ce dernier point constituant une véritable mini-révolution politico-sociologique. Elle recherche la participation de tous (hommes, femmes, personnes âgées...), accepte l'expression de voix extérieures, recherche une dynamique collective...

Elle se tourne aussi vers le thème de l'environnement. Mais cette question n'est pas simple. À la base, pour les pêcheurs et pour les insulaires, il s'agit de garder la mer comme un endroit ressource qui permet de vivre, comme un lieu encore relativement propre qu'il faut garder. Selon l'une des premières phrases de Hashimoto Hisao 橋本久男, l'un des pêcheurs les plus combatifs, et représentant au tribunal la TNK poursuivie par Chūden alléguant les pertes causées par l'empêchement de son chantier, « combler la baie de Ta-no-ura est une question vitale pour nous pêcheurs dont la vie repose sur la mer» (Ankei 2012: 129).

Et il ajoute : "Je suis fier de la mer de Kaminoseki où je suis né. Une centrale nucléaire et cette magnifique mer pleine de vie ne peuvent coexister. J'ai le droit de vivre pacifiquement sur Iwai-shima et de poursuivre ma vie grâce à mes activités de pêche " (ibid.). Même si Hashimoto intègre ensuite les phrases désormais incontournables sur ce qu'il faut "laisser aux générations futures ", c'est bien de la mer présente, immédiate et nourricière dont il parle.

Fin 1999, l'Association de défense de la nature de Naga-shima (Nagashima no shizen o mamoru-kai 長島の自然を守る会) est fondée par une femme très active, Takashima Minori 高島美登里. Elle devient membre de l'UICN (Union internationale de conservation de la nature) en 2012. Sollicitant les interventions scientifiques, elle met en place des conférences ou colloques. Un navire de Greenpeace passe dans les eaux locales le 18 avril 2000. 
Plusieurs savants japonais multiplient les interventions sur les thématiques écologiques à partir des années 2000. Parmi eux, on trouve Ankei Yūji 安溪遊地, originaire de la région, enseignant à l'université départementale de Yamaguchi, biologiste de formation qui se tourne vers une réflexion anthropologique. Il avance le concept de " diversité bioculturelle " qu'il définit comme étant « un ensemble de plantes et d'animaux dont la diversité a été maintenue par les valeurs culturelles et les comportements locaux, indigènes, qui, en retour, dépendent de leur biodiversité locale " (ibid. : 127). Ce concept reste néanmoins problématique, car on ne sait pas si cette biodiversité concerne le patrimoine génétique des espèces vivantes, leur abondance, leur qualité ou bien l'ensemble de ces éléments qui ne se situent pas sur le même plan. Quant à l'idée même de "bioculture ", elle laisse songeur...

L'écosystème de la région d'Iwai-shima n'a rien d'exceptionnel malgré la beauté des paysages. La mer de Suō où baignent les îles de Kaminosekichō a été épargnée par les grandes pollutions industrielles. Le phénomène d'eutrophisation des " marées rouges " (akashio 赤潮) visible plus au nord y est moindre, les eaux y sont plus claires. Le rejet des eaux de refroidissement de la centrale n'altèrerait pas la composition chimique de l'eau, mais contribuerait à la réchauffer. Cet impact sur l'écosystème marin, sur la faune en particulier, est l'objet de discussions, mais ce sujet n'est pas évoqué par Ankei Yūji. En revanche, celui-ci se concentre sur des espèces animales, certains oiseaux, des gastropodes et des brachiopodes qu'il considère en danger.

La Société écologique du Japon (SÉJ) dont il est membre et d'autres associations naturalistes comme le Comité de conservation de la société ornithologique du Japon signalent la question lors de la Convention sur la diversité biologique pendant la COP10 qui se tient à Nagoya en octobre 2010. Celle-ci attire l'attention sur « les effets dévastateurs » que la centrale nucléaire aurait «sur les vies des communautés et sur l'environnement maritime».

La résolution portée en mars 2000 par la SÉJ pour protéger le site de Ta-no-ura est acceptée en 2001 par le gouvernement japonais qui vient juste d'instaurer une nouvelle législation sur l'environnement (1999). Mais cela n'empêche en rien Chūden et les pouvoirs publics de poursuivre leur action... L'absence d'une espèce emblématique à protéger, démarche chère aux naturalistes, n'est toutefois pas un handicap pour les habitants qui considèrent leur milieu comme un tout. 


\section{L'effet insulaire}

L'effet minoritaire des opposants est en partie compensé par l'effet insulaire. Non seulement le projet des deux immenses tours de refroidissement vient détruire le paysage, boucher la vue, changer l'atmosphère, modifier le milieu, mais il nargue les insulaires qui habitent juste devant, contrairement à un grand nombre de centrales nucléaires au Japon qui sont cachées des villages. Il s'apparente à une agression, laquelle est vécue comme une indignité. Il renforce le sentiment insulaire d'être ignoré, car se trouvant déjà à l'écart.

Nasu Keiko 那須佳子, une photographe qui a longuement suivi la lutte d'Iwai-shima, indique le moment où elle a compris pourquoi ces paysans et ces pêcheurs vieillissants sont restés sur la brèche de l'opposition : le jour où, à l'occasion d'une manifestation, l'un des porte-parole de Chūden leur a demandé s'ils comptaient vraiment vivre de leur travail, de leurs champs et de leur pêche ${ }^{13}$. Ils se sont sentis humiliés. Selon Nasu Keiko, les habitants d'Iwai-shima n'ont en outre pas vraiment conscience de la valeur de l'argent. Cette forme de détachement conjuguée à leur attachement pour le terroir explique leur engagement.

Les enjeux matériels mobilisés par le projet de centrale nucléaire concernent deux domaines : le foncier et l'espace maritime, soit 160 ha de terres et 14 ha de terre-plein. Concernant le foncier terrestre, les pouvoirs publics japonais qui rechignent à recourir aux procédures d'expropriation cherchent habituellement à négocier (Bourdier \& Pelletier 2000). Mais cette méthode qui pouvait sembler favorable dans cette zone montueuse, forestière et peu cultivée s'est révélée difficile. Le morcellement complexifie la procédure. Certains terrains appartiennent à des personnes d'Iwai-shima, donc des opposants.

Des propriétaires fonciers se constituent en association (13 janvier 1985) pour défendre leurs propres terrains ainsi que les terrains communaux (iriaiken 入会権 $\left.{ }^{14}\right)$. Les soutiens aux opposants sont invités à acheter un arbre. Une maison en bois est construite sur le site pour accueillir les

13. Bouteiller (2018, op. cit.).

14. "Association des propriétaires fonciers contre le nucléaire" (Genpatsu ni hantai suru jinushikai) créée le 13 janvier 1985 avec 32 membres (Yamato 2013 : 24). 
rassemblements, comme symbole d'une résistance permanente. En 2003, elle est rebâtie et équipée de panneaux solaires. Des propriétaires de Shidai portent plainte contre le déclassement de leurs terres ainsi que de certaines parcelles relevant des communaux (5 février 1999). Après une série de procès qui vont jusqu’à la Cour suprême, ils sont déboutés (14 avril 2008). Le prêtre antinucléaire du Shōhachimangū refuse le déclassement de la terre agricole et forestière de son domaine. Mais la série de procès qu'il intente (novembre 2004) jusqu'à la Cour suprême est perdue, car la justice considère sa plainte comme irrecevable (15 septembre 2010).

Concernant l'espace maritime, l'enjeu est beaucoup plus fort. D'abord, parce que l'élément liquide offre moins de prises à la juridiction propriétaire et complique les choses. Ensuite, et surtout, parce que ce sont les pêcheurs qui sont les plus opposés à la centrale. De cela, les dirigeants politiques et économiques en sont rapidement conscients, bien qu'ayant sous-estimé la capacité de résistance de ces hommes de la mer.

Par "pêcheurs", il faut entendre la "coopérative des travailleurs de la pêche " (gyogyō rōdō kumiai 漁業労働組合). Cet organisme est essentiel. En effet, depuis la loi de 1901 confirmée en 1949, toute personne ou tout groupement désireux de pratiquer une activité halieutique doit s’y inscrire obligatoirement ${ }^{15}$. La gestion de l'espace maritime côtier lui est en outre confiée, ce qui revient à en faire une "propriétaire maritime " de facto.

Toute modification de ce "merritoire " doit donc passer par la coopérative de pêche afin que, via la Préfecture, celle-ci cède à l'État ou à une entreprise privée ses «droits de pêche " (gyogyō hoshōryō 漁業保証料), c'est-à-dire des droits d'usage qui deviennent des droits fonciers maritimes. Or toute cession doit recevoir l'accord des deux tiers des coopérateurs. C'est dire le pouvoir que ceux-ci ont entre leurs mains. C'est dire aussi l'attention qu'ils reçoivent de la part des acteurs intéressés.

Le secteur halieutique est d'ailleurs l'un des rares au Japon à avoir échappé en partie à la politique systématique de privatisation des sols, des ressources, des espaces et des " communs " (iriai) qui remonte à l'ère Meiji. La force collective ainsi que le côté "monde à part " des communautés de pêcheurs et des insulaires ont permis une telle exception qui a souvent disparu en

15. Il ne s'agit donc pas de coopérative à proprement parler, mais de guilde ou de prudhommie. 
forêt ou en montagne. La problématique du droit d' "accès à la plage " (irihama-ken 入り浜権), c'est-à-dire à la mer, constitue même pour l'État et le capital japonais l'une des principales épines du pied socio-spatiales dans leur politique de développement, d'étatisation ou de privatisation.

$\mathrm{Si}$ les pouvoirs publics peuvent accorder toutes les autorisations possibles pour la centrale nucléaire (achat de terrains, permis de construire, enquête environnementale...), tant que les pêcheurs n'acceptent pas concrètement les indemnisations financières qui correspondent à l'abandon de leur droit d'usage sur la mer, rien n'est possible pour Chūden.

\section{L'enjeu crucial des coopératives de pêche et des indemnisations}

Huit coopératives de pêche sont concernées par le projet de centrale sur une zone qui s'étend jusqu'à une trentaine de kilomètres au-delà du site prévu (communes de Hikari 光, Ushi 牛, Tabuse 田布施, Hirase 平瀬, Kaminoseki, Murotsu, Shidai, Iwai-shima). Le fait qu'on en trouve quatre sur la seule commune de Kaminoseki-chō pourrait jouer en faveur des opposants en affaiblissant la majorité politique de la municipalité de Kaminoseki favorable au nucléaire, mais ce ne sera pas le cas. Une seule coopérative s'oppose du début jusqu'à la fin : celle d'Iwai-shima (CPI), tandis que celle de Shidai est déchirée en interne. Sur le rivage du San.yōdō, certains pêcheurs des coopératives se sentent certes concernés, mais, ayant déjà accepté le principe des indemnisations lors de projets antérieurs de terre-plein, ils sont prisonniers de leur logique.

Les travaux préliminaires de Chūden sont contestés en justice, où les jugements ne sont pas en faveur des plaignants, et sur place par des blocages et des occupations diverses. Les opposants ont choisi l'action non-violente : accrochage des personnes aux engins de travaux, à des arbres, à des grillages ou à des mâts, flottille de bateaux de pêche entourant les navires de Chūden. Des grands-mères et des grands-pères font face à des mastards, gardes mobiles de l'État ou bien vigiles payés par Chūden. L'un des temps forts est l'arrêt des travaux en octobre 2009 à la suite d'une mobilisation très active sur le site du projet.

Sur le plan électoral, la situation se stabilise. Moins d'inscrits, moins de voix, mais les rapports de force se maintiennent. S'instaure comme un 
match entre deux candidats : Kashiwabara Shigemi, pro-nucléaire, élu maire en 2003, réélu en 2007 et en 2011, à chaque fois face à Yamato Sadao, défait. Puis seul candidat en 2015 et en 2019. L'équilibre entre les deux camps en nombre de conseillers municipaux oscille entre les pros et les antis : 10/6 (en 1998), 8/6 (en 2002), 9/5 (en 2006), 9/3 (en 2010), 10/2 (en 2014) et $7 / 3$ (en 2018).

Les indemnisations deviennent un enjeu central : symbolique et concret, porteur de fierté ou de renoncement. La CPI opère sur deux tableaux : elle maintient son refus d'un procédé qu'elle considère comme illégitime; elle le porte en justice à partir du moment où Chūden et les autorités tentent d'isoler la CPI des sept autres coopératives et de lui faire accepter ce qu'elle ne veut pas dès l'origine. Au début de l'année 1998, le bureau 107 qui émane du regroupement régional des coopératives de pêche entame les négociations auprès de Chūden. La CPI refuse d'y participer et lui dénie toute légitimité de le faire en son nom.

Le 13 juin 2000, trois membres de la CPI déposent une plainte en justice contre la recevabilité du contrat d'indemnisations passé entre Chūden et le bureau 107. Ce contrat, signé le 27 avril 2000, prévoit 1,255 milliard de yens d'indemnisations (près de dix millions d'euros). Chūden en verse aussitôt la moitié au bureau 107 (15 mai 2000). Répartissant les montants, le bureau 107 envoie 540 millions de yens à la CIP, laquelle les refuse et les renvoie. Les autorités tentent alors d'isoler la CPI en imposant un regroupement des coopératives de pêche au sein d'une instance supérieure, départementale. La CIP, qui maintient son autonomie de droit et de fait, s'y oppose (26 janvier 2005).

Le tribunal d'Iwakuni (département de Yamaguchi) rejette la plainte de la CPI, mais il reconnaît le permis et la liberté des droits de pêche (23 mars 2006). La Haute cour de Hiroshima confirme le rejet sans reconnaître la liberté des droits (15 juin 2007). L'affaire remonte jusqu’à la Cour suprême qui confirme la première décision du tribunal d'Iwakuni (30 octobre 2008). Autrement dit, les trois pêcheurs et la CPI avec eux sont déboutés. Du coup, 74 habitants d'Iwai-shima, estimant que le versement d'indemnisations aux pêcheurs est illégal, car accompli en dehors des règles, portent plainte contre le permis de construction de terre-plein accordé à Chūden (20 octobre 2008).

Face à la répression constante, aux décisions judiciaires qui ne leur sont pas favorables et aux montants d'indemnisation qui sont colossaux pour 
des familles souvent modestes et âgées, la pression devient de plus en plus forte. L'essoufflement se profile et le désarroi guette. La population vieillit, et le combat devient plus âpre. Pour Tao Hisako, alors âgée de soixante-dix ans, " cela devient difficile de continuer à se battre quand chacun porte une canne " (Tabuchi 2011).

Mais l'accident de Fukushima change la donne. Le 2 septembre 2011, le Premier ministre Nōda déclare que toute construction nouvelle de centrale nucléaire au Japon est «en réalité difficile " (genjitsuteki ni konnan 現実的 に困難). Trois jours après, le gouverneur de Yamaguchi reprend la même phrase à propos de Kaminoseki. Dans les faits, le projet est gelé, mais pas abandonné. L'expression officielle de "en réalité difficile " est néanmoins ambiguë, car difficile ne veut pas dire impossible, tandis que le terme japonais de konnan comprend une notion d' "embarras ".

Réunie en assemblée générale le 28 février 2012, la CIP est tentée par les indemnisations qui sont finalement peut-être bonnes à prendre. Elle refuse de justesse, par 31 voix contre 21 (Yamato 2013 : 124). On imagine que les tensions et les frustrations ont été vives. Une accalmie survient après le Kanmai de 2016 puisqu'un compromis est trouvé au tribunal entre les opposants et Chūden qui avait porté plainte pour préjudices ${ }^{16}$. Le maire Kashiwabara remarque même que "nous pourrions penser à construire une cité (machizukuri) sans nucléaire ", déclaration faite, il est vrai, juste après l'accident de Fukushima (Tabuchi 2011).

\section{La difficulté des alternatives}

La dignité, la fierté et l'indépendance l'emportent chez les pêcheurs et les insulaires. Mais pour beaucoup, cela ne suffit pas. Certains essaient d'aller jusqu'au bout de leurs idées. Puisque s'opposer au nucléaire aboutit à s'interroger sur l'approvisionnement en électricité ou en énergie, puis sur la

16. "Kaminoseki genpatsu kōji, Chūden, seikyū no zengaku hōki, sonbai soshō hantaijūmin to wakai » (Les travaux nucléaires à Kaminoseki, retrait du montant total demandé par Chūden, compromis avec les opposants à propos de la plainte pour préjudice), Chügoku shinbun, 31 août 2016. 
conception de l'économie en général, certains d'entre eux se lancent dans des alternatives économiques.

Quelques-uns, dont fait partie Yamato, veulent équiper l'île d'une centrale solaire. D'autres, majoritaires, le refusent, considérant que, comme pour une centrale nucléaire, ce genre d'équipement constituera une drogue à la subvention et entraînera l'île dans une spirale de développement et de pollution indésirable. Ils proposent des solutions comme l'agriculture biologique, l'éco-tourisme ou le wwoofing (système de travail à la ferme gratuit en échange du gîte et du couvert). Les choix pour l'avenir créent des tensions au sein des familles. Chez les Kunihiro 國弘, le frère aîné Tadatoshi, paysan récoltant de nèfles, prône une forme d'auto-suffisance, tandis que le frère cadet Hideto 秀人 et sa femme Yūko 優子 revenus sur l'île en 2000 veulent faire tourner l'auberge qu'ils ont héritée de la famille, donc accueillir des touristes.

Le retour de certains jeunes qui n'ont pas voulu laisser les anciens surtout les anciennes, vu la composition genrée de la pyramide des âges - seuls face aux gardes civils favorise un certain renouveau. Sur une dizaine d'années, une quarantaine de personnes se sont installées pour habiter l'île (Ricketts 2014 : 40). Parmi elles, de jeunes couples. Quelques enfants naissent, mais pas assez pour rouvrir l'école. Et encore faut-il que les nouveaux habitants soient intégrés. Car ils arrivent avec leur mode de vie métropolitain, leur système de valeurs et leur aspiration à une société différente. Selon qu'ils aient ou non des ascendants sur Iwai-shima, leur place est différente. S'y ajoutent toutes les histoires relationnelles qui sont habituelles dans les petites sociétés.

Certains insulaires reprochent aux nouveaux venus jeunes leur manque d'ardeur au travail. La présence de "maisons vides » (akiya 空家) désertées par l'exode rural et qui tombent parfois en ruine ouvre un débat sensible : doit-on les attribuer aux nouveaux venus, gratuitement ou avec un loyer? De quel montant? Doit-on contacter les descendants des propriétaires? Que fait-on avec les assurances? Et s'il y a un incendie? Ces questions à la fois prosaïques et concrètes montrent les difficultés à s'adapter à une nouvelle situation et à se diriger vers un contexte où légalité comme légitimité ont été repensées.

La lutte antinucléaire a, en outre, bouleversé l'une des caractéristiques de la société japonaise traditionnelle, le patriarcat, à la suite du rôle considérable qu'y ont pris les femmes. Même si celles-ci semblent rester au second 
plan dans le folklore traditionnel et Kanmai, bien qu'opérant dans les coulisses ou animant la parade finale du shagiri しゃぎり où elles chantent et dansent, leur importance est palpable. On le sent dans leur façon de s'exprimer, leur gestuelle, leur attitude. Leur présence. Selon Nasu Keiko, ce " nouvel équilibre est important pour que cela marche bien dans ces petites îles éloignées où la communauté est petite, étroite et conservatrice ${ }^{17}$ ".

Des femmes comme Sakamoto Ikuko 坂本育子, Shōmoto Emiko 正本 笑子, Hayashi Masue ou Takebayashi «Tami-chan » Tamiko 竹林民子 ont été motrices dans la lutte. Lorsque certains pêcheurs furent à deux doigts d'accepter les subsides de Chūden, les femmes ont fait barrage. Tami-chan, par exemple, une battante, est un personnage haut en couleurs sillonnant les rues de la bourgade sur sa pétrolette. Partie comme ouvrière dekasegi à Kobe à l'âge de quinze ans, elle est revenue dans l'île avec son expérience et un autre regard sur le monde. Au décès de son mari qui était un pêcheur reconnu, elle a pris la relève de son activité. C'est la seule femme pêcheur sur Iwai-shima, ce qui lui vaut le respect.

L'un des enjeux reste démographique : car l'île continue de perdre des habitants. De 478 habitants en 2012, la population d'Iwaishima est en effet passée à 348 habitants en 2020. La dégringolade démographique continue de concert avec un vieillissement accru puisque les trois quarts de la population ont plus de 65 ans. Il faut cependant tenir compte du chiffre des foyers, dont le nombre est resté relativement stable, autour de trois cents au cours des années 2000. Cela semble signifier un maintien malgré tout des familles, quoique plus réduites. On peut aussi comparer avec l'île voisine de Ya-shima, certes moitié moins grande en superficie, mais dont la population est passée de 667 habitants en 1955 à vingt et un en 2019.

Pour autant, certains sur Iwai-shima pensent que le nombre n'est pas le problème. Selon eux, l'île peut vivre sous une certaine auto-subsistance, mâtinée de quelques échanges et d'un commerce de niche. L'idée est envisageable pour la génération adulte guidée par le militantisme antinucléaire et pour les nouveaux venus solidaires, attirés de surcroît par la beauté de l'île. Les anciens ne peuvent guère les aider. Leur engagement a été vaillant, ils ont droit au repos.

17. Nasu Keiko, correspondance personnelle, 18 novembre 2016. 
Mais quid des jeunes qui n'auront pas connu le combat antinucléaire et qui finiraient par s'ennuyer sur l'île comme certains autrefois ? Plus prosaïquement, comment les jeunes hommes et les jeunes femmes trouveront-ils des partenaires s'ils sont peu nombreux et confinés sur leur confetti? S’ils se mettent en couple et ont des enfants, si l'école est toujours fermée et si un projet pédagogique n'est pas impulsé, auront-ils l'envie ou le courage de poursuivre?

Rien ne nous dit en outre que le projet de centrale ne va pas être relancé dans un Japon néo-conservateur et néo-nationaliste qui n'a pas tardé à rouvrir quelques réacteurs nucléaires (neuf en juin 2018, répartis sur cinq sites). Le gouvernement Abe l'a fait au nom du respect des accords de Paris de la COP21, pour l'indépendance énergétique du Japon et la lutte climatique, politique confirmée par son successeur. Lors de son premier discours devant la Diète le 26 octobre 2020, le nouveau Premier ministre Suga Yoshihide 菅義偉 déclare à son tour que le Japon « réduira à zéro ses émissions de gaz à effet de serre d'ici 2050 ", en "favorisant au maximum le recours aux énergies renouvelables » et en "poursuivant une politique axée sur la sûreté en matière de nucléaire civil ». Autrement dit, celui-ci n’est pas abandonné.

Le maintien assumé du nucléaire civil se combine en réalité à la perspective du nucléaire militaire, fait passé pratiquement inaperçu auprès des observateurs obnubilés par la question climatique (Pelletier 2020). Car, même après l'accident de Fukushima qui aurait pu refroidir le peuple japonais et ses dirigeants, qui l'ont certes été en partie mais en partie seulement, l'État japonais entend, et même plus que jamais, se doter de l'arme atomique. C'est l'une des raisons pour laquelle il refuse de signer le Traité international sur l'interdiction des armes atomiques de juillet 2017 (Janvier 2020).

Quelques semaines plus tard lors d'une session parlementaire le 21 janvier 2021, le Premier ministre Suga précise d'ailleurs les choses : «En accord avec notre position selon laquelle il est nécessaire de poursuivre un chemin constant et réaliste vers le désarmement nucléaire, le Japon n’a pas l'intention de signer le traité [des Nations unies bannissant les armes atomiques $]^{18}$. " Le Japon rompt discrètement mais implacablement son rôle symbolique de pays pacifiste dans le monde. Les habitants d'Iwai-shima suivront-ils?

18. "Japan doubtful about nuclear ban treaty", Anadolu Agency, 22 janvier 2021, d'après Kyōdō News Agency. 


\section{Bibliographie}

\section{Ankeı Yūji 2012}

« Nuclear Power Plants and Biocultural Renaissance: a Case Study of Iwaishima Island in the Seto Inland Sea of Japan ", Journal of Marine and Island Cultures, 1 : 126-130.

ArImA Tetsuo 有馬哲夫 2012

Genpatsu to genbaku, Nichi-Bei-Ei kaku busō no antō 原発と原爆「日·米·英」核武装 の暗闘 (Nucléaire et atome, lutte sourde entre Japon, États-Unis, Royaume-Uni), Tokyo, Bungeishunjū 文藝春秋.

\section{BerTHIeR François 1981 \\ Masques et portraits - Arts du Japon, Paris, POF.}

Bourdier Marc \& Pelletier Philippe (dir.) 2000

L'Archipel accaparé, la question foncière au Japon, Paris, EHESS.

DUSINBERRE Martin 2012

Hard Times in the Hometown, a History of Community Survival in Modern Japan, Honolulu, University of Hawai'i Press.

FuKUSHIMA Kikujirō 福島菊次郎 1989 Setonaikai ritō monogatari 瀬戸内海離島 物語 (Histoires des îles éloignées de la mer intérieure de Seto), Tokyo, Shakai hyōronsha 社会評論社.

\section{ICHIOKA Yuji 1988}

The Issei, the World of the First Generation Japanese Immigrants, 1895-1924, New York, The Free press.
IRIE Hidechika 入江英親 1975

Umi o wataru matsuri, Iwaishima to

Kunisaki betsugūsha no kanmai 海を渡る 祭一祝島と国東別宮社の神舞 (La Fête qui traverse la mer, le Kanmai d'Iwai-shima et du sanctuaire annexe de Kunisaki), Tokyo, Keiyūsha 慶友社.

IsHIKAWA Tomonari 石川友紀 1997

Nihon imin no chirigakuteki kenkyū :

Okinawa, Hiroshima, Yamaguchi 日本移民 の地理学的研究一沖縄·広島·山口 (Étude géographique de l'émigration japonaise : Okinawa, Hiroshima, Yamaguchi), Ginowan, Yōju shorin 榕樹書林.

\section{JANVIER Romain 2020}

"La Fission du nucléaire japonais : entre tensions régionales, pacifisme constitutionnel et ambiguïtés politiques », Lyon, ENS-IEP, Master Asioc.

\section{JoBIN Paul 2017}

«"Nuclear Gypsies" in Fukushima Before and After 3/11 », in MACDowelL Laurel (dir.), Nuclear Portraits: People, Communities and the Environment, Toronto, Toronto University Press : 274-311.

\section{Kaminoseki-chō shihensan iinkai 上関} 町史編纂委員会 1985

Kaminoseki-chō-shi 上関町史 (Histoire de Kaminoseki-chō), Hiroshima, Daiiichi hōki shuppan 第一法規出版.

KUNIHIRo Yūko 國弘優子 \& KUNIHIRo Hideto 國弘秀人 2016

Happĩ airando Iwaishima tsūshin はっぴー あいらんど祝島通信 (Correspondance d'Iwai-shima, une île heureuse), 4 vol., 
Nishi-Agenoshō, Mizunowa shuppan みずのわ出版.

\section{LesbiRel Hayden S. 1998}

Nimby Politics in Japan: Energy Siting and the Management of Environmental

Conflict, Ithaca, Cornell University Press.

Matsubara Toshiyuki 松原利幸 et al. 1971 « Iwai-shima » 祝島, Chiriken Setouchi chosa shirīzu 地理圏瀬戸内調査シリーズ, 4, Kwansei gakuin daigaku chirikenkyūkai 関西学院大学地理研究会: 69-130.

\section{MARTZEL Gérard 1982}

Le Dieu masqué, fêtes et théâtre au Japon, Paris, POF.

NoRDYKe Eleanor C. \&

Matsumoto Y. Scott 1977

«The Japanese in Hawaii: a Historical and Demographic Perspective ", Hawaiian Journal of History, 11 : 162-174.

\section{Pelletier Philippe 1992}

L'Insularité dans la mer Intérieure japonaise, Bordeaux, Cret-Ceget, collection « Îles et archipels », 16.

\section{Pelletier Philippe 2007}

Le Japon, géographie, géopolitique et géohistoire, Paris, Sedes, collection «Impulsion ».

\section{Pelletier Philippe 2013}

« De la guerre totale à la guerre de Fukushima ", Outre-Terre, revue européenne de géopolitique, 35/36: 399-437.

\section{Pelletier Philippe 2020}

Effondrement \& capitalisme vert, la collapsologie en question, Paris, Nada.

\section{O Hosok 2010}

«Cultural Analysis of the Early Japanese Immigration to the United States during Meiji to Taishō Era (1868-1926) », thèse de doctorat à I'Oklahoma State University.

RICKETTS Robert ロバート・リケット 2014 " "Henkyō" no chikara, KaminosekiIwaishima no genba hōkoku kara » 「辺境」の力, 上関·祝島の現場報告から (Le pouvoir de la « marge », rapport de terrain sur Kaminoseki-Iwaishima), Jōeikai \& shimpojium : posuto-genpatsu jidai o ikiru 上映会\&シンポジウム:ポスト 原発時代を生きる (Films et colloques, vivre dans une ère post-nucléaire), Wakō daigaku 和光大学 : 31-44.

\section{Stanlaw James 2006}

« Japanese Emigration and Immigration, from the Meiji to the Modern », in ADACHI Nobuko (dir.), Japanese Diasporas, Using Pasts, Conflicting Presents and Uncertain Futures, Londres, Routledge : 34-51.

\section{TABUCH Hiroko 2011}

« Japanese Island's Activist Resist Nuclear Industry's Allure », The New York Times, 27 août.

\section{Yамато Sadao 山戸貞夫 2013 Iwaishima no tatakai, Kaminoseki genpatsu hantai-undō shi 祝島のたたか い上関原発反対運動史 (La Bataille d'Iwai- shima, histoire du mouvement anti- nucléaire à Kaminoseki), Tokyo, Iwanami shoten 岩波書店.}


